\title{
Stress Conditions and Mental Health Status of International Students Studying in Japan
}

\author{
Meixuan Song, Keiji Tabuchi, Toshio Kobayashi \\ Department of Health Development, Institute of Biomedical and Health Sciences, Hiroshima University, Hiroshima, Japan \\ Email address: \\ songmeixuangongye@yahoo.co.jp (M. Song), tabk2@hiroshima-u.ac.jp (K. Tabuchi), tkobaya@hiroshima-u.ac.jp (T. Kobayashi)
}

\section{To cite this article:}

Meixuan Song, Keiji Tabuchi, Toshio Kobayashi. Stress Conditions and Mental Health Status of International Students Studying in Japan. Science Journal of Public Health. Vol. 6, No. 3, 2018, pp. 100-105. doi: 10.11648/j.sjph.20180603.16

Received: April 16, 2018; Accepted: June 19, 2018; Published: June 26, 2018

\begin{abstract}
In recent years, as international students studying at universities are increasing in Japan, so maintaining mental health of them living in unfamiliar countries is an important issue. The purpose of this research was to clarify the situation of stress and the condition of mental health among international students. We conducted a self-check question survey for 67 international students who came from 10 countries living in Japan, aged between 20 and 45 (average age was 26.4 years). The contents of the survey were personal attributes, life stress, revised UCLA loneliness scale (20-80 points), and depressed state self-rating scale (CES-D) (0-60 points). For statistical analysis, Pearson correlation analysis with IBM SPSS 22.0 was used. The average years of residence in Japan was 2.07 years. Stressor of daily life were "Japanese language skill shortage" and "various procedures are troublesome". Stressor of economic was "weight of economic burden". Stressor of study were "graduation thesis" and "the field of study and research is difficult". Hereafter, stressor of private expense students was having to do part-time jobs to maintain their lives. When the Japanese language ability was high, the stress on daily life and study was low, but the stress of part-time jobs was higher. It was conceivable that the international students with higher Japanese ability, the demand on work will be also higher. The CES-D score was 15.57 on average and $37.3 \%$ with depressed tendency (16 points or more). The positive correlation was found between CES-D and the stressor of daily life $(\mathrm{r}=0.311, \mathrm{p}<0.05)$, stressor on study $(\mathrm{r}=0.246, \mathrm{p}<0.05)$, loneliness $(\mathrm{r}=0.383, \mathrm{p}<0.01)$. In addition, the average score of international students' loneliness scale was 42.72 points. The positive correlation was also found between loneliness and the stressor of daily life $(r=0.311, p<0.05)$. Based on these results is necessary to pay attention to international students' stressors on daily life, study, loneliness, and mental health state. In this research, the actual situation of international student's daily life, economic aspect, and academic stress were clarified. Providing support to maintain their mental health is important to prevent the tendency of depression for international students who living with strong stress and loneliness.
\end{abstract}

Keywords: International Student, Stress, Mental Health, Loneliness

\section{Introduction}

According to the survey by the Japan Student Services Organization as of May 1, 2017, the total number of international students including Japanese graduate schools, undergraduates, junior colleges, technical colleges, vocational schools, preparatory courses, Japanese language education institutions were 267,042 people, increased by 27,755 people, $11.6 \%$ compared with the same time in 2016.

International students are easy to fall into negative emotions such as loneliness and stress because of the new living environments, circle of acquaintance, impacts of different cultures, etc. In this research, to clarify the actual condition of stress of international students and the present condition of mental health, we grasp the stressor, the feeling of loneliness and the depression tendency of daily life for international students living in Hiroshima City International Student Hall and investigated social support and stress coping method.

\section{Subject and Method}

\subsection{Subject}

With the cooperation of the International Student Hall in Hiroshima City, we conducted a self-check question survey 
for 67 international students living in Japan (collection rate $67 \%$ ) who came from 10 countries, aged between 20 and 45 (average age was 26.4 years). The survey period were November to December in 2017. In addition, since the survey covers international students of multiple nationalities, both Japanese and English were conducted.

\subsection{Contents and Method}

\subsubsection{Contents}

1) Personal attributes

As shown in Table 1, the data of international students on gender, nationality, age, marital status, living together with any other or not, duration of living in Japan, Student status, Status of study abroad, and Japanese language ability were clarified.

2) Stress on daily life

With reference to "measure items on cross-cultural adaptation" wrote by Tanaka and "Questionnaire on what international students are feeling trouble" wrote by Fujii et al. (2004), the survey contents in this research were daily life, cross-cultural adaptation (Japanese language, Japanese culture, environment, physical condition etc.), things about economics, things about part-time jobs, and things about study. Each item was evaluated by the four-item method of 1 "Not troubled" 2 "Slightly troubled" 3 "Troubled" 4 "Very troubled".

3) The Revised UCLA Loneliness Scale

For the situation of loneliness of international students, The Revised UCLA Loneliness Scale (Russell et al.) in Japanese translation version (Kudo, Nishikawa et al. 1983) was used. This scale is made up of 20 items and it is four-item method of "never" 1 point to "often" 4 points. The score ranges from maximum of 80 points to minimum of 20 points. The score was higher as the feeling of loneliness was stronger.

4) Depressed state self-rating scale (CES-D)

Stress response of international students was measured by using depression state self-rating scale CES-D (Island, 1998). It is a two-dimensional scale including four positive items. Question items as few as 20 questions can be used easily. Psychometrically high specificity and positive predictive value, high validity and clinical usefulness have been confirmed. It has a characteristic that it can be used as a mental health check and mental health survey for a wide range of subjects (15 years old and over) with less burden on subjects. Questions about the frequency of symptoms in the past week, four-item method of "less than one day" 0 point, " 5 days or more" 3 points. The score ranges from a maximum of 60 points to a minimum of 0 points. The score was higher as the depressed tendency was stronger, and 16 points as the cutoff value. Score as 16 points or more lived with depressed tendency were evaluated.

5) Assistive interpersonal relationship composition
For regarding the situation of assistance interpersonal relationships (social support) for international students living in Japan, assistance interpersonal question paper "Studies on life stress and health of Asian students" reported by Asakura etc. (1993) was used. To grasp about social support when they fall into trouble.

6) Stress coping

The method of coped stress in daily life of international students was evaluated by using the questionnaire created by Asakura et al. (1993). The contents of the survey were how to deal with daily life stress and how to relieve stress.

\subsubsection{Method}

In order to clarify the contents mentioned above, this research conducted unsigned self-check question survey for international students living in Hiroshima City International Student Hall. For statistical analysis, descriptive statistics and Pearson correlation analysis with IBM SPSS 22.0 were used.

\section{Results and Discussion}

\subsection{Personal Attribute}

From the personal attributes of the subjects, percentage for male were $40.3 \%$, for female were $59.7 \%$. International students were from ten countries, without the subjects who did not respond. Among them, 67.2\% from China, 10.4\% from Indonesia, 3.0\% from Philippines, 1.5\% from Myanmar, Malawi and Mongolia, 4.5\% from Bangladesh, 3.0\% from Korea, Vietnam and $1.5 \%$ from Egypt. Missing value was $4.5 \%$ (Table 1). The average age of the subjects was $26.40 \pm$ 4.81 years old, the minimum age was 20 years old, the maximum age was 45 years old. In the marital status, percentage of married people was $25.4 \%$, unmarried people was $74.6 \%$. Regarding the presence of living together with any other or not, $16.4 \%$ of them responded that they were living with others, $82.1 \%$ of them responded that they were living alone, and $1.5 \%$ was missing value. The mean value of duration of living in Japan was $2.07 \pm 1.60$ years. On student status, $6.0 \%$ for language schools, $1.5 \%$ for vocational schools, $16.4 \%$ for undergraduates, $14.9 \%$ for research students, $41.8 \%$ for master's course, $14.9 \%$ for doctoral students, $4.5 \%$ for others (exchange students). On the status of study abroad, $11.9 \%$ with government-sponsored international students, $71.6 \%$ with private expense students and $16.4 \%$ with international students who received scholarship from Japan. Regarding Japanese language ability, the subjects who responded "low" accounted for $26.9 \%$, the subjects who responded "ordinary" people accounted for $38.8 \%$, the subjects who responded "high" accounted for $34.3 \%$.

Table 1. Personal attribute.

\begin{tabular}{lllll}
\hline Personal attribute & Item & frequency & percent & mean \\
\hline \multirow{2}{*}{ Gender } & Male & 27 & 40.3 \\
\multirow{2}{*}{ Nationality } & Female & 40 & 59.7 \\
& China & 45 & 67.2 \\
\hline
\end{tabular}




\begin{tabular}{|c|c|c|c|c|}
\hline Personal attribute & Item & frequency & percent & mean \\
\hline & Indonesia & 7 & 10.4 & \\
\hline & Philippines & 2 & 3.0 & \\
\hline & Myanmar & 1 & 1.5 & \\
\hline & Malawi & 1 & 1.5 & \\
\hline & Mongolia & 1 & 1.5 & \\
\hline & Bangladesh & 3 & 4.5 & \\
\hline & Korea & 2 & 3.0 & \\
\hline & Vietnam & 2 & 3.0 & \\
\hline & Egypt & 1 & 1.5 & \\
\hline & Missing & 3 & 4.5 & \\
\hline Age & & & & $26.40 \pm 4.81$ \\
\hline \multirow{3}{*}{ Marital status } & Married & 17 & 25.4 & \\
\hline & Unmarried & 50 & 74.6 & \\
\hline & Yes & 11 & 16.4 & \\
\hline \multirow[t]{2}{*}{ Living with any other or not } & No & 55 & 82.1 & \\
\hline & Missing & 1 & 1.5 & \\
\hline \multirow[t]{4}{*}{ Duration of living in Japan } & & & & $2.07 \pm 1.60$ \\
\hline & Language school & 4 & 6.0 & \\
\hline & Vocational school & 1 & 1.5 & \\
\hline & Undergraduate & 11 & 16.4 & \\
\hline \multirow[t]{5}{*}{ Student status } & Research student & 10 & 14.9 & \\
\hline & Master's Course & 28 & 41.8 & \\
\hline & Doctoral students & 10 & 14.9 & \\
\hline & Others (exchange students) & 3 & 4.5 & \\
\hline & Government-sponsored & 8 & 11.9 & \\
\hline \multirow{3}{*}{ Status of study abroad } & Private expense & 48 & 71.6 & \\
\hline & Scholarship from Japan & 11 & 16.4 & \\
\hline & Low & 18 & 26.9 & \\
\hline \multirow{2}{*}{ Japanese language ability } & Ordinary & 26 & 38.8 & \\
\hline & High & 23 & 34.3 & \\
\hline
\end{tabular}

\subsection{Stress on Daily Life}

It was suggested top items with high score of stress are "things about go on the next stage of education or obtain a job", "lack of Japanese language skill", "economic burden is heavy", "cost of food is high", "about graduation theses", "research and study areas are difficult", "The progress of study and research is not good", "various procedures are annoying". These items were suggested to be basic and severe issues when living in Japan. On the other hand, the items with low score of stress were "cannot adapt the climate and environment of Japan", "cannot understand Japanese culture ", "a lot of homework". That might be because many of the international students came from Asia, the climate and environment in their home country is not too much difference from Japan. And there might be some similar parts in culture, so they are not difficult to overcome for them.

Things about part-time jobs were shown in table 2, 67.2\% of the subjects had part-time job, and the other $32.8 \%$ of the subjects didn't have part-time job. To those who had a part time job, top items with high score of stress were "part-time job takes much time", "Frequent part-time job", "I feel very busy and must do a lot of work at part-time job". It is considered that private expense students didn't get any support of scholarship, school expenses and living expenses are lost by themselves, and with the high prices in Japan, it is inevitable that they have to dedicated to their part - time jobs to support their lives without hold up their studies.

Table 2. Part-time job.

\begin{tabular}{lll}
\hline & Frequency & Percent \\
\hline Yes & 22 & 32.8 \\
No & 45 & 67.2 \\
Total & 67 & 100.0 \\
\hline
\end{tabular}

\subsection{The Revised UCLA Loneliness Scale}

Regarding the situation of loneliness of international students, the maximum score were 71 points, the minimum score were 22 points, and the mean score was $42.72 \pm 11.79$ (Table 3), according to the survey results. In other studies, it was found that the third year of university students' loneliness was high as 36.92 points, 38.79 for adult men and 35.38 for adult women. It proofed that the loneliness of international students was high. Among 20 items, the four items with the highest score were "I do not have much in common with people around me", "I am not the indispensable one among close associates", "There were no people who really understood me." The item "I do not have much in common with people around me" and "I am not the indispensable one among close associates" reflected social loneliness (Russell, 1984). From that results, it considered 
that more appropriate social support for international students is necessary.

Table 3. Loneliness

\begin{tabular}{llll}
\hline Range & Minimum & Maximum & Mean \\
\hline $20-80$ & 22 & 71 & $42.72 \pm 11.79$ \\
\hline
\end{tabular}

\subsection{Depressed State Self-Rating Scale (CES-D)}

The depression state self-assessment scale CES-D (Island, 1998) evaluates that there is a depression tendency with 16 points as a cut-off value and 16 points or more. According to the subject's response, the average score for depression is $15.57 \pm 9.14$, and $37.3 \%$ of them whose score were 16 points or more. One of them said that he recently planned to go to a psychiatric clinic. Therefore, it considered that the international students' mental health were not in good status.

As international students were shocked by different cultures, difficulties on study, economical burdens and had to frequently join their part-time jobs, they were not only the physical feeling of exhaustion, but also can't insure their free time. Further, with the impact of living with strong loneliness, it is considered that they were easy to fall into depression tendency.

\subsection{Assistive Interpersonal Relationship Composition}

Regarding the assistive interpersonal relationships, "family/relatives" accounted for 48.9\%, "international students from their home countries living in Japan" accounted for $42.0 \%$, these two items which seems to provide a relatively large amount of assistance, and it were considered as a support source for international students. On the other hand, the item "Japanese friends / acquaintances" and "school teachers" accounted for $22.2 \%$ and $19.4 \%$, respectively. Takai (1989) found that the relationship between Japanese people is complicated and difficult to understand, the Japanese attitude towards foreigners is also closed and passive, and Japanese attitudes toward foreign students from Asian countries are unfriendly. There were indications that foreign students would give up on forming intimate and effective human relations support relationship with Japanese (Zhou, 1995).

\subsection{Stress Coping}

Regarding the methods of cope with stress in daily life, the one which be most taken was "watching movies and listening to music", accounting for $47.8 \%$. "Rest at home, sleep" and "Eat delicious food" account for $46.3 \%$ as well, always be taken. On the other hand, it is found that the number of subjects who cope with stress by "traveling" was as small as $9.0 \%$ (Table 4). When stress accumulated, coping by watching movies, listening music, having rest and enjoying delicious meal for refreshing were showed effective a lot. However, because of traveling is not only need enough time but also take a lot of money, that thought it is not a good choice for coping with stress for international students.

Table 4. Stress coping

\begin{tabular}{lll}
\hline Coping & Frequency & percent \\
\hline Bear with & 10 & 14.9 \\
Rest at home, sleep & 31 & 46.3 \\
drink alcohol & 7 & 10.4 \\
Write diary & 2 & 3.0 \\
Do sports & 11 & 16.4 \\
Watch movies, listen music & 32 & 47.8 \\
Enjoy my interest, do thing what I love & 21 & 31.3 \\
Eat delicious food & 31 & 46.3 \\
Consult with close friends & 17 & 25.4 \\
Enjoy going out with friends & 13 & 19.4 \\
Shopping & 7 & 10.4 \\
Travel & 6 & 9.0 \\
\hline
\end{tabular}

\subsection{Correlation}

A negative correlation was found between Japanese ability and stress of daily life $\cdot$ cross-cultural adaptation $(r=-0.317, p$ $<0.01)$, stress of study $(\mathrm{r}=-0.267, \mathrm{p}<0.05)$. On the other hand, a positive correlation was found between Japanese ability and stress of part - time job $(\mathrm{r}=0.389, \mathrm{p}<0.01)$. Based on these results it was conceivable that the international students with higher Japanese ability, the demand on work will be also higher.

Table 5. Correlation between social support, life stress, UCLA and CES-D.

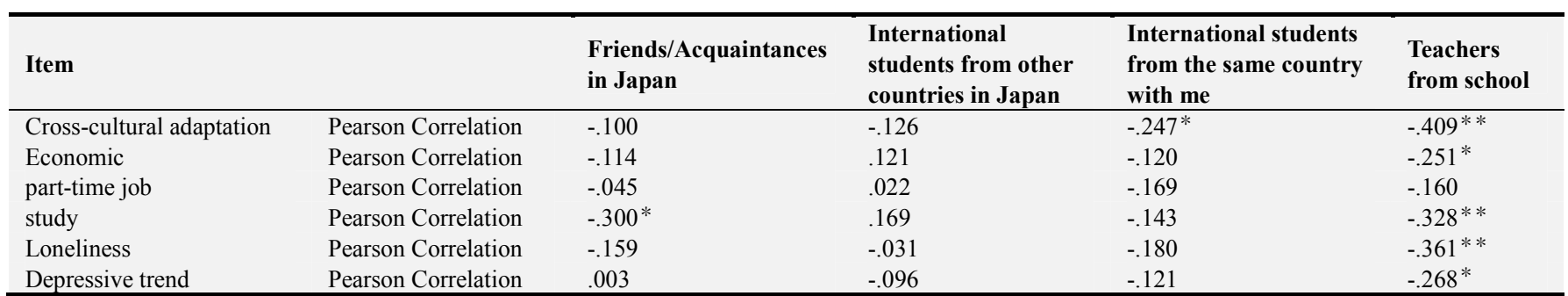

Table 5. Continued

\begin{tabular}{|c|c|c|c|c|c|}
\hline Item & & $\begin{array}{l}\text { Staff in the place } \\
\text { where I live in }\end{array}$ & $\begin{array}{l}\text { Friends, acquaintance } \\
\text { in my home country }\end{array}$ & Family/relatives & No one \\
\hline Cross-cultural adaptation & Pearson Correlation & $-.356 * *$ & $-.245^{*}$ & -.060 & -.057 \\
\hline Economic & Pearson Correlation & -.240 & -.165 & .156 & -.154 \\
\hline part-time job & Pearson Correlation & $-.354^{*}$ & $-.321^{*}$ & .040 & .046 \\
\hline study & Pearson Correlation & -.113 & $-.306^{*}$ & .067 & -.209 \\
\hline Loneliness & Pearson Correlation & $-.281^{*}$ & $-.274^{*}$ & .006 & $.309^{*}$ \\
\hline Depressive trend & Pearson Correlation & $-.271^{*}$ & $-.253^{*}$ & -.225 & $.315^{*}$ \\
\hline
\end{tabular}


A positive correlation was found between loneliness and stress of daily life $\cdot$ cross-cultural adaptation $(r=0.339$, $p$ $<0.01)$ and part-time jobs $(\mathrm{r}=0.295, \mathrm{p}<0.05)$. A positive correlation was also found between CES-D and stress of daily life $\cdot$ cross-cultural adaptation $(\mathrm{r}=0.311, \mathrm{p}<0.05)$, stress of study $(\mathrm{r}=0.246, \mathrm{p}<0.05)$, loneliness $(\mathrm{r}=0.383, \mathrm{p}<0.01)$. Based on these results, it was necessary to pay attention to international students' stress on daily life, study, loneliness, and mental health state.

The correlation about assistance interpersonal relationships (social support), a positive correlation was found between the item "friends - acquaintances in home country" and "duration of living in Japan" ( $r=0.263, p<0.05)$. It is means that longer international students live in Japan, more they can adapt the life in Japan. On the other hand, it was thought that fewer help can be provided from their friends acquaintances in their home countries. Also, negative correlations were found between the three items "Teachers from school" "Staff of the place where I live in" "Friends and acquaintances in home country" and stress of daily life - cross-cultural adaptation, loneliness and depression tendency (CES-D) (Table 5). Therefore, it is considered that international students are extremely necessary to get social support, especially support from the school teachers, the staff of the place where international students live in and the friends · acquaintances in their home country.

\section{Conclusion}

In this research, an investigator questionnaire survey was conducted for international students living in Hiroshima City's International Student Hall. The stress situation and the coping method of stress on daily life, cross-cultural adaptation, economics, part-time job and study were clarified. In addition, the mental health status of international students and the influencing factors were also clarified. Furthermore, it is considered that providing more appropriate support is very important for international students.

\section{References}

[1] Iwasaki Kori (2015) Policy of attracting international students in Japan - from the viewpoint of altitude accepting talented foreigners - Pacific Rim Business information RIM 2015 Vol. 15 No. 58.

[2] Masahiro Miguti, Midori Egawa (1994) Study on life stress status and it's relevant factors of international students studying in Japan. Presentation summary of Japan Educational Society Conference (46), 74-75.

[3] Cecilia, Ikeguchi (2012) Internationalization of Education \& Culture Adjustment The Case of Chinese Students in Japan Intercultural Communication Studies XXI: 2.

[4] Takashi Asakura, Li Chen (1993) Study on life stress and health of Asian international students. Bulletin of Tokyo Gakugei University the 5th department, Art Health Sports science, 45: 97-103.
[5] Makiiko Mori, Miki Aoyanagi (2007) Health-Related Behavior of Chinese students Studying in Japan and Present Circumstances of Support System. Bulletin of Ex-Japan Red Cross College of Nursing No. 21, pp. 33 to 41

[6] Chen Jindi, Takataya Kumiko (2008) The Characteristics of social support of mainland Chinese students in Japan and their effect on their study and daily life. Yamanashi Nursing Journal Vol. 6 No. 2.

[7] Tomoko Tanaka, Jiro Takai, Takaya Kohyama, Chiho Muranaka, Takehiro Fujihara (1990) A Study on the adjustment of international Students in Japan (1) - A factor analysis of cross-cultural adjustment Scale - Bulletin of Integrated Arts and Sciences, Hiroshima University III, Vol. 14, 77-94.

[8] Yukina Shimoda, Tomoko Tanaka (2007) Cultural distances recognized by international students in Japan: from the perspectives of individualism-collectivism and high/low context communication. Education for international students (12), 25-36, 2007-12.

[9] Keiko Fujii, Masami Kadokura (2004) What is the difficulty for international students - from questionnaire survey in the first half year of 2003 - 8-4 - 12 Yokohama National University international student center bulletin (1994-2005) No. 11.

[10] KaoRuren Chen (2011) The impact of interpersonal self-efficacy on interpersonal stress coping in Chinese students in Japan. Kyushu University Psychological Research 2011, Vol. $12,113-120$.

[11] Tracy Rundstrom Williams (2005) Exploring the Impact of Study Abroad on Students' Intercultural Communication Journal of Studies in International Education, Vol. 9 No. 4.

[12] Tomoko Sonoda (2011) A study on mental health and social support of Gunma University foreign students: from the results of a retest of Ohashi (2005) - Gunma University international education and research center issue No. 10 1-15

[13] Jiro Takai (1989) Summary of the study on adaptation of international students living in Japan. Bulletin of the Faculty of Education, Nagoya University (Educational Psychology), Vol. 1989 36: 139-147

[14] Tomoko Tanaka, Jiro Takai, Hirofumi Minami, Takehiro Fujihara (1990) A Study on the adjustment of international Students in Japan (2) - Implications of Social network formation on newly arrived Students - Bulletin of Integrated Arts and Sciences, Hiroshima University III, Vol. 14, 95-113.

[15] YuMei Tang (2004) Research on intercultural adaptation process of Chinese students in Japan - from the perspective of difficulties in interpersonal behavior, Bulletin of International Cultural Studies 2004, 10: 293-328.

[16] Masumi Oka, Hiromi Fukada, YuHui Zhou (1996) Purpose and adaptation of Chinese private students to study abroad. Okayama University economic society magazine 27 (4), 1996, 25-49.

[17] Tokiyo Inai, (2010) For the improvement of overseas students' support - On the basis of questionaire survey on the Chinese overseas students-, Research bulletin 54 55, 71 92

[18] JERRY S. CARLSON, KEITH F: WIDAMAN (1988) The effects of study abroad during college on attitudes toward other cultures. Inrernalmnol Journal of Inwcultural Relatrons, Vol 12, p, I-17. 1988 
[19] Midori komatu (2013) The relationship between Chinese students' negative perceptions, dissatisfaction, and causal attribution toward their association. Human culture creation science review Vol. 15.
[20] YuZhi Xiao (2018) Impact of the value of studying abroad on the feeling of adaptation and fulfillment of student life in Japan - For private students studying abroad in Japan Bulletin of the Graduate School of Education, Waseda University Separate volume 25-2. 